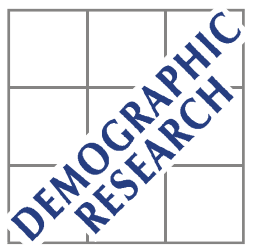

Demographic Research a free, expedited, online journal of peer-reviewed research and commentary in the population sciences published by the Max Planck Institute for Demographic Research Konrad-Zuse Str. 1, D-18057 Rostock · GERMANY www.demographic-research.org

DEMOGRAPHIC RESEARCH

VOLUME 23, ARTICLE 2, PAGES 41-62

PUBLISHED 06 JULY 2010

http://www.demographic-research.org/Volumes/Vol23/2/

DOI: $10.4054 /$ DemRes.2010.23.2

Descriptive Findings

\title{
The differential impact of mortality of American troops in the Iraq War: The non-metropolitan dimension
}

Katherine J. Curtis

Collin F. Payne

(C) 2010 Katherine J. Curtis \& Collin F. Payne.

This open-access work is published under the terms of the Creative Commons Attribution NonCommercial License 2.0 Germany, which permits use, reproduction \& distribution in any medium for non-commercial purposes, provided the original author(s) and source are given credit.

See http:// creativecommons.org/licenses/by-nc/2.0/de/ 


\section{Table of Contents}

1 Introduction $\quad 42$

2 Data and methods $\quad 43$

2.1 Deaths 43

2.2 Enlistments $\quad 44$

2.3 Person-Years 44

2.4 Deployments 44

3 Disaggregated death rate of US military personnel in Iraq 45

$4 \quad$ Understanding higher non-metropolitan death rates 49

4.1 Enlistment 49

4.2 Rank 53

$\begin{array}{lll}4.3 & \text { Race/Ethnicity } & 55\end{array}$

5 Conclusion $\quad 57$

$\begin{array}{lll}6 & \text { Acknowledgements } & 59\end{array}$

$\begin{array}{ll}\text { References } & 60\end{array}$ 


\title{
The differential impact of mortality of American troops in the Iraq War: The non-metropolitan dimension
}

\author{
Katherine J. Curtis ${ }^{1}$ \\ Collin F. Payne ${ }^{2}$
}

\begin{abstract}
This study investigates the disproportionate impact of mortality among United States troops in Iraq on rural communities. We advance scholarly research and popular accounts that suggest a non-metropolitan disadvantage by disaggregating the risk of mortality according to the metropolitan status of their home county and by examining potential sources of variation, including enlistment, rank and race or ethnicity. Results show that troops from non-metropolitan areas have higher mortality after accounting for the disproportionate enlistment of non-metropolitan youth, and the non-metropolitan disadvantage generally persists across military branch and rank. Moreover, most of the differential is due to higher risks of mortality for non-metropolitan African American and Hispanic military personnel, compared to metropolitan enlistees of the same race or ethnicity.
\end{abstract}

\footnotetext{
${ }^{1}$ University of Wisconsin - Madison. E-mail: kcurtis@ssc.wisc.edu.

${ }^{2}$ University of Pennsylvania.
} 


\section{Introduction}

Considerable attention has been given to mortality among United States troops in the Iraq War (2003 to present), especially the differential impact made by death among troops. A recent study estimated the risk of death for US troops in Iraq, according to several individual characteristics including military branch, rank, sex, age, and race or ethnicity (Buzzell and Preston 2007) and found that the greatest risk of death was experienced by the Marines, the enlisted, males, the young, and Hispanics. Some of the differences in risk of death correspond with trends in the larger society (e.g., sex) while others are specific to the military (e.g., branch and rank). Other researchers and journalists have focused on the potential differential impacts of deaths in the Iraq conflict for specific sub-populations of American society, including rural populations and lower-income groups (e.g., Mark 2007; O'Hare and Bishop 2006; see also Zeitlin, Lutterman, and Russell 1973 for an explicit focus on class and poverty). In their 2006 report on rural soldiers, O'Hare and Bishop (2006) connect these two sub-populations by linking military involvement to the poor economic opportunities that characterize many rural areas. The current study is concerned with the potential disproportionate impact of mortality in Iraq for the rural population, and extends previous research by empirically estimating the extent of the differential impact, and taking initial steps to investigate the sources of variation.

The disproportionate impacts of deaths in Iraq are important to consider for at least two reasons. First, rural communities in the United States have a long and active history of military involvement, yet they have fewer resources to deal with the consequences of war. Research has shown that rural communities lack the necessary support services for families suffering loss (Helseth 2007a). Indeed, service providers in rural areas are not able to directly serve their communities because, in part, they have been deployed to Iraq and Afghanistan (Helseth 2007b). Second, disproportionate military deaths may also perpetuate the conditions in rural communities that encourage rural youth to serve in the military and put themselves at risk of death. Military deaths among the rural population diminish the available labor force-which makes an impact on a community's ability to attract industry and reduces household earning potential, which puts families at greater risk of living in poverty. Limited labor force opportunity and economic instability are oft-cited reasons for military enlistment (Bachman et al. 2000; Dale and Gilroy 1984; O'Hare and Bishop 2006; Teachman, Call and Segal 1993; for a contrasting view, see Kane 2005, 2006).

In the current analysis, we address the question of whether rural communities are more greatly affected by mortality in the Iraq War compared to urban communities, by disaggregating mortality data by the non-metropolitan status of the reported home counties of the deceased, and estimating whether troops from rural communities have a 
greater risk of death than troops from urban communities. Our analysis covers all US military deaths since the invasion of Iraq, March 20, 2003, through December 31, 2007, reported by iCasualities and the Department of Defense (DOD). We use census definitions of metropolitan and non-metropolitan counties to examine enlistment and death rates for all military personnel disaggregated by non-metropolitan status in addition to several risk factors associated with higher death rates, namely military branch, rank within branch and race or ethnicity. The approach enables us to examine the extent to which the human costs of the Iraq War differentially impact rural communities.

\section{Data and methods}

The following sub-sections detail the data and methods used to calculate deaths, enlistment, person-years lived, and deployments by metropolitan or non-metropolitan status. These four components form the basis for our reported figures, tables, and calculations.

\subsection{Deaths}

Data on deaths include all deaths in troops deployed to Iraq from the start of the Iraq War on March 20, 2003 to December 31, 2007. We compiled death records from iCasualties (http://icasualities.org/oif/Details.aspx) and the Department of Defense (DOD: http://siadapp.dior.whs.mil/personnel/CASUALTY/oif_date_of_death_list.pdf), giving preference to iCasualties information in instances of discrepancy between the two sources. In several cases, DOD listed the soldiers' military base as the hometown, whereas iCasualities reported the place where they enlisted. Death records include information on cause of death (combat, non-combat violent, and non-combat disease), race, rank, branch of service, age, sex, and hometown. To classify individuals' places of origin as metropolitan or non-metropolitan, we rely on 2003 USDA-ERS county level definitions, which are in turn derived from the census 2000 definition of metropolitan. ${ }^{3}$

\footnotetext{
${ }^{3}$ Non-metropolitan/metropolitan and rural/urban designations do not perfectly align. The designations, however, do correlate with one another and we use the term non-metropolitan as a parallel to rural. "Metropolitan" and "non-metropolitan" is defined differently than "urban" and "rural." Metropolitan counties are defined as having an urbanized area, and all counties are determined to be either metropolitan or nonmetropolitan. Urban populations are classified by more stringent rules based on population density thresholds. County populations are described as being "percent urban" or "percent rural." (http://www.ers.usda.gov/Briefing/Rurality/NewDefinitions/ and http://www.ers.usda.gov/Briefing/Rurality/WhatisRural/). Accessed May 2008.
} 


\subsection{Enlistments}

Rates of enlistment for metropolitan and non-metropolitan areas are estimated using county-level recruitment data from the National Priorities Project (NPP) (http://www.nationalpriorities.org/nppdatabase_tool). ${ }^{4}$ These data contain the number of enlistees by branch of service for each county in the United States, allowing us to create an overall metropolitan/non-metropolitan proportion of recruits by branch. Data availability varies by year as follows: metropolitan/non-metropolitan enlistment proportions for Army troops are available for 2004, 2005, 2006, and 2007; enlistment proportions for Navy and Air Force troops are available for 2004 and 2005; and enlistment proportions for Marines is available only for 2005. The available metropolitan/non-metropolitan proportions are used to show the ratio of enlistees to the population age 18-24 by rural concentration using estimates from Census 2000 SF1.

\subsection{Person-Years}

The DOD reported quarterly counts of troops deployed in Iraq from March 31, 2003 to December 31, 2007 (http://siadapp.dmdc.osd.mil/personnel/MILITARY/Miltop.htm). With these data we calculated the total number of person-years lived in each branch of service during the study period, using the linear interpolation method described in Preston, Heuveline, and Guillot (2001). We estimated the total number of metropolitan and non-metropolitan person-years lived in each branch of service by applying the metropolitan-non/metropolitan enlistment proportions by branch of service (described above) to the overall count of person-years lived by branch of service of troops deployed to Iraq. We then aggregate this estimate to obtain the total number of person years lived by metropolitan or non-metropolitan status. These estimates serve as the denominator for the death rate calculations and as the basis for the measure of deployments.

\subsection{Deployments}

In keeping with Buzzell and Preston (2007), we use total deployments as the measure of exposure when calculating the metropolitan/non-metropolitan relative risk of death. We adjusted the calculations of exposure to account for changes in deployment lengths by branch of service and over the time period studied. For Army troops, deployments were

\footnotetext{
${ }^{4}$ These data have been used in the popular media and by Kane $(2005 ; 2006)$, and were accessed April 2008.
} 
12 months from March 20, 2003 to April 11, 2007, and 15 months thereafter; for Air Force troops, deployments were 3 months from March 2003 to September 2004, and 4 months thereafter; for Navy and Marine troops, deployments were 7 months. To clarify, the number of troops deployed is used to calculate the total number of person-years lived among deployed personnel, as elaborated in the previous section. The number of deployments, in contrast, is the number of times soldiers were sent on a tour of combat duty. Total deployments (exposures) were calculated by multiplying the number of deployments per year by branch of service to the person-years lived in that branch. Unfortunately, the number of enlistees disaggregated by both race and ethnicity and non-metropolitan/metropolitan status is not available in the DOD or NPP data. To estimate the proportions of deployments by race and metropolitan/non-metropolitan status, we applied the age-specific (18-24 years-old) urban/rural proportions by race from Census 2000 SF4 to the overall troop counts by race, found in Table B-24 of the report on the Population Representation in the Military Services 2005 (http://humrro03.securesites.net/poprep/poprep05/appendixb/b_24.html).

\section{Disaggregated death rate of US military personnel in Iraq}

Data from the Department of Defense (DOD) show 3,853 United States military personnel died between the beginning of the Iraq War on March 20, 2003 and December 31, 2007. Of these deaths, 898 (23\%) are personnel from non-metropolitan counties - $21 \%$ of the total US population and nearly $17 \%$ of the population age 20 to 34 was rural in 2000. We examine the cause-specific rate of death using person-years lived as the denominator which is derived from the quarterly count of troop strengths in Iraq reported by the Department of Defense, as described in section 2.3. The quarterly troop count does not report troop strengths broken down by metropolitan/nonmetropolitan status, however. We applied the metropolitan/non-metropolitan enlistment proportions by branch of service to the number of person-years lived in that branch to calculate the annual cause-specific death rate per 1,000, described in section 2.2. The disaggregated death rates by non-metropolitan status of the reported home county for the deceased military and the civilian population (age 20-34) are reported in Table 1.

A higher death rate is observed for the non-metropolitan sub-population of the military and the civilian population across all causes of death. Consistent with previous research, non-combat violent deaths (i.e., accidents, suicides, and homicides) and disease-related deaths are higher among the United States population than the military population (Buzzell and Preston 2007). Results also demonstrate that the US non- 
metropolitan population has higher death rates than the metropolitan population, especially violent deaths. ${ }^{5}$

Table 1: Comparison of death rate by general cause among troops in Iraq to death rate of US population by non-metropolitan/metropolitan status: Iraq War, 20 March 2003 - 31 December 2007

\begin{tabular}{lcccc}
\hline & \multicolumn{3}{c}{ Annual death rate per 1,000 } \\
\cline { 2 - 5 } & $\begin{array}{c}\text { Combat } \\
\text { deaths }\end{array}$ & $\begin{array}{c}\text { Non-combat } \\
\text { violent deaths }\end{array}$ & $\begin{array}{c}\text { Deaths from } \\
\text { disease }\end{array}$ & Total \\
\hline Death rate among troops in Iraq & 3.43 & 0.58 & 0.20 & 4.20 \\
$\quad$ Total & 3.27 & 0.54 & 0.19 & 4.00 \\
Metropolitan & 4.09 & 0.71 & 0.22 & 5.01 \\
Non-metropolitan & - & & & \\
US sex-standardized death rate, ages & $20-34,2003$ & 0.90 & 0.42 & 1.32 \\
Total & - & 0.86 & 0.42 & 1.28 \\
Metropolitan & - & 1.11 & 0.45 & 1.55 \\
Non-metropolitan & & & & \\
\hline
\end{tabular}

Turning to military deaths, the troop data show that military personnel from nonmetropolitan areas are at a disadvantage relative to personnel from metropolitan counties. The military population has a lower rate of death from non-combat violence (i.e., .58 for military versus .90 for civilians), but the higher rate of non-metropolitan deaths observed in the civilian population persists in the troop population. For example, the death rate is more than $20 \%$ higher for non-metropolitan military and civilian populations compared to metropolitan populations. Moreover, and especially pertinent to popular discussions about the imbalanced costs of war, a markedly higher combat death rate is observed for non-metropolitan troops compared to metropolitan troops. The total death rate for all troops in Iraq due to combat is 3.43 per 1,000 individuals, yet the combat-related death rate for non-metropolitan personnel is 4.09 per 1,000 versus 3.27 for metropolitan troops.

All causes combined, the total death rate for non-metropolitan troops is just over 5 deaths per 1,000. In contrast, the total death rate for metropolitan troops is 4 deaths per 1,000 . The higher death rate for non-metropolitan troops suggests that the consequences

\footnotetext{
${ }^{5}$ Data from the National Center for Health Statistics (Eberhardt et al. 2001) show that deaths from accidents and suicides are higher among non-metropolitan populations whereas homicides are notably higher for metropolitan populations.
} 
of war are disproportionately felt by non-metropolitan communities. The difference in death rates is a single person (per 1,000), yet the raw numeric impact of loss is greater for a non-metropolitan community than a metropolitan community due simply to the lower population concentration that defines non-metropolitan communities. While there are dramatic consequences for the families and friends of the deceased regardless of community size, each death has a greater impact on the non-metropolitan community given population size and, very likely, the density of kinship and social network characteristics of less urban places (White and Guest 2003).

Nuances on the rural disadvantage are revealed in an analysis of mortality by branch of service, reported in Table 2. Marines have the highest death rate of all branches; the rate is nearly twice that of the next highest branch, the Army. The rankings persist when disaggregating the troop population by non-metropolitan status. Marines have the highest death rate for all non-metropolitan and metropolitan troops followed by Army troops. There is no statistical difference in the death rates between non-metropolitan and metropolitan Marines, but non-metropolitan Army personnel and all non-metropolitan personnel from all branches combined have a higher death rate than metropolitan personnel. The ratio of deaths further highlights the differences experienced by non-metropolitan troops. For example, Army troops have a higher death rate than Navy and Air Force troops, and a larger ratio of these deaths is comprised of individuals from non-metropolitan counties. The higher death rates observed for nonmetropolitan troops, again, shows that the impacts of the Iraq War are differentially felt by non-metropolitan communities.

Table 2: Death rate and relative mortality levels by military branch and nonmetropolitan/metropolitan status, Iraq War, 20 March 2003 - 31 December 2007

\begin{tabular}{lccccc}
\hline & \multicolumn{2}{c}{ Annual death rate per $\mathbf{1 , 0 0 0}$} & \multicolumn{2}{c}{$\begin{array}{c}\text { Ratio of death rate to } \\
\text { total death rate }\end{array}$} \\
\cline { 2 - 6 } & Non-metropolitan & Metropolitan & Total & Non-metropolitan Metropolitan \\
\hline Army & 5.44 & 4.31 & 4.54 & 1.20 & 0.95 \\
Marine Corps & 8.38 & 7.69 & 7.82 & 1.07 & 0.98 \\
Navy & 1.23 & 0.86 & 0.93 & 1.32 & 0.93 \\
Air Force & 0.62 & 0.44 & 0.48 & 1.30 & 0.92 \\
Total & 5.01 & 4.00 & 4.20 & 1.19 & 0.95 \\
\hline
\end{tabular}

Note: Non-metropolitan/metropolitan differences in death rates are statistically significant $(p<.05)$ for Army and total deaths 
Differences in the relative impact made by deaths among metropolitan and nonmetropolitan troops in the Iraq War are further illustrated in Figure 1. The number of combat deaths per county population age 20-34 is plotted for all US counties. ${ }^{6}$ Shaded areas have suffered at least one death in Iraq; the lightest shading corresponds with counties losing less than a .5 standard deviation from the mean (less than 1\%) of its age-specific population, whereas the darkest shade highlights counties that have lost more than a 1.5 standard deviation of its age-specific population (the highest proportion observed was Mineral County, Colorado at $1.1 \%$ ). Counties with no shading suffered no loss as of December 31, 2007.

\section{Figure 1: Distribution of combat deaths per county population, Iraq War, 20 March, 2003 - 31 December, 2007}

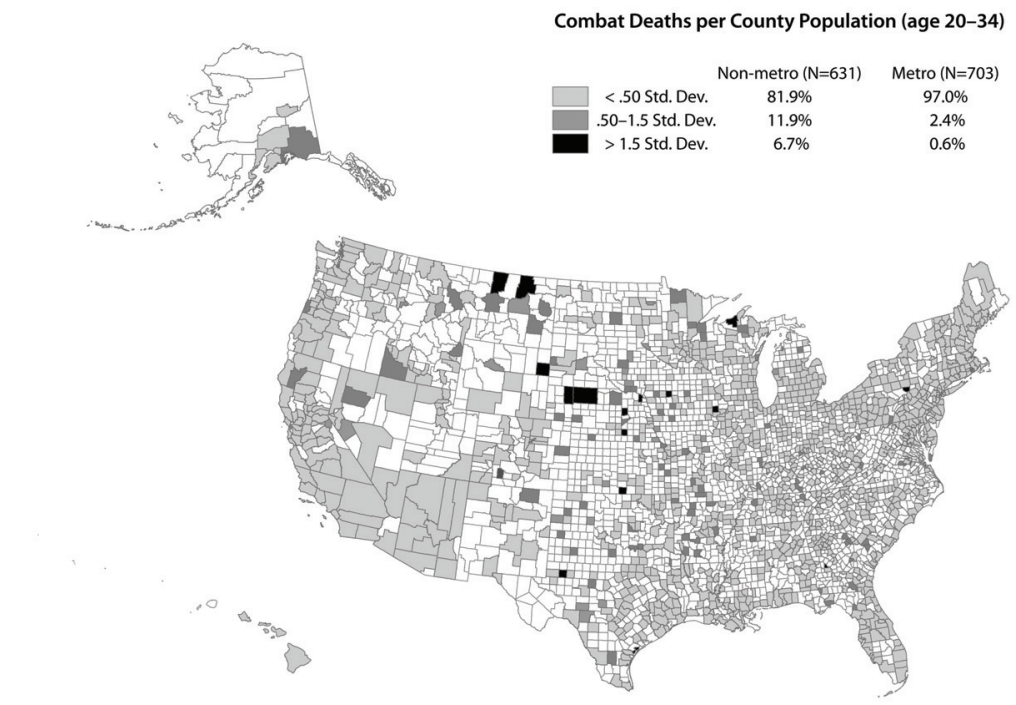

Source: Total combat deaths from iCasualties and county population in 2000 from U.S. Census Bureau.

Metropolitan counties experience a lower impact of mortality in Iraq than nonmetropolitan counties. For example, $97 \%$ of all metropolitan counties fall within the low-impact category; the impact of losses in Iraq is lower than the average loss and less

\footnotetext{
${ }^{6}$ The values in Figure 1 represent the total number of military combat deaths per population age 20-34 for each county and, thus, differ from the death rates reported in Tables 1 and 2.
} 
than a percent $(.6 \%)$ of all metropolitan counties lost more than the average. In comparison, $18 \%$ of non-metropolitan counties fall within the higher-impact categories (11.9 and 6.7). This is intuitive, given the smaller population base to which military deaths are applied; yet the social and economic implications for these communities cannot be dismissed, and are likely to be magnified by the lower population size that is less able to absorb these losses. That is, a smaller number of deaths in a lowerpopulated area will have a larger impact relative to a higher-population place that experiences the same number of deaths. The loss of even a low number of individuals from a small community will have a dramatic impact, given the relative size of the agespecific pool of, for example, potential earners or marriage partners.

The figure also illustrates that deaths in the Iraq War are not evenly distributed across US counties. The South has higher enlistment than any other region in the US (Kane 2006; Segal and Segal 2004), yet only counties in Texas suffered the highest relative loss. The higher-impact category is largely concentrated in the Great Plains (which includes Texas) and the Upper Midwest regions. Of the states within these regions, however, only Montana has been identified as having one of the highest numbers of recruits relative to the youth population (Kane 2006; Segal and Segal 2004).

Counties with the five highest relative and absolute losses are reported in Table 3 separately for non-metropolitan and metropolitan counties. In absolute terms, losses are higher for metropolitan counties (e.g., 105 troop deaths for Los Angeles County, California, versus 9 deaths for Oceana County, Michigan). Yet in relative terms, losses among the non-metropolitan counties are greater than metropolitan counties; the highest percentage loss is over $1 \%$ for the top non-metropolitan county (Mineral County, Colorado) versus .23\% for the top metropolitan county (Falls Church City, Virginia).

\section{Understanding higher non-metropolitan death rates}

\subsection{Enlistment}

Disproportionate enlistment is often identified as a potential explanation for the nonmetropolitan communities experiencing the brunt of military deaths (e.g., O'Hare and Bishop 2006). It is important to note, however, that the death rates reported in this study account for uneven enlistment between non-metropolitan and metropolitan counties. The rates are standardized and, thus, hold the base population constant; the death rate is 5 per 1,000 non-metropolitan individuals and 4 per 1,000 metropolitan individuals. Still, we draw on data from the National Priorities Project (NPP) to examine differences in enlistment according to two dimensions used in earlier research-non- 
Curtis \& Payne: The differential impact of mortality of American troops in the Iraq War

metropolitan/metropolitan status and rural concentration-to demonstrate the differences in military investment across the non-metropolitan/metropolitan dimension.

Table 3: Top 5 absolute and relative losses for US counties by nonmetropolitan/metropolitan status, Iraq War, 20 March 2003 - 31 December 2007

\begin{tabular}{lcclcc}
\hline \multicolumn{7}{c}{ Non-metropolitan } & \multicolumn{5}{c}{ Metropolitan } \\
\hline County & $\mathbf{N}$ & $\mathbf{\%}$ & County & $\mathbf{N}$ & $\%$ \\
\hline Oceana, MI & 9 & 0.21 & Los Angeles, CA & 105 & 0.00 \\
Lewis and Clark, MT & 6 & 0.06 & Harris, TX & 51 & 0.01 \\
Mohave, AZ & 6 & 0.03 & San Diego, CA & 48 & 0.01 \\
Jefferson, NY & 6 & 0.02 & Maricopa, AZ & 43 & 0.01 \\
Citrus, FL & 5 & 0.04 & Bexar, TX & 35 & 0.01 \\
\hline & $\mathbf{5}$ highest relative losses & & \\
\hline County & $\mathbf{N}$ & $\%$ & County & $\mathbf{N}$ & $\%$ \\
\hline Mineral, CO & 1 & 1.08 & Falls Church City, VA & 4 & 0.23 \\
Garfield, MT & 1 & 0.56 & Dixon, NE & 1 & 0.10 \\
Alpine, CO & 1 & 0.47 & Aransas, TX & 3 & 0.10 \\
Edwards, TX & 1 & 0.37 & Fairfax City, VA & 5 & 0.10 \\
Haakon, SD & 1 & 0.37 & Crosby, TX & 1 & 0.08 \\
\hline
\end{tabular}

Enlistment for 2004-05 by place type is reported in Table 4. Rural concentration reflects the proportion of the county total population that resides within rural areas. ${ }^{7,8}$ The percentage representation of recruits coming from non-metropolitan counties is relatively consistent across the military branches and is proportionate to the US nonmetropolitan population. Non-metropolitan enlistment is highest for the Air Force (21\% of all enlistment), yet there is only a 3 percentage-point range across the branches $(18 \%$ of all Navy enlistment is non-metropolitan). Census figures show that about $20 \%$ of the United States total population is non-metropolitan, and $17 \%$ of the US population age 18-24 is rural (U.S. Census Bureau 2002). The ratio of enlistment relative to the youth population (age 18-24), also reported in Table 4, suggests that enlistment is

\footnotetext{
${ }^{7}$ We depart from Kane's (2006) measure of rural concentration by treating the county as the unit of observation rather than Zip Code Tabulated Areas (ZCTA).

8 "Urban" and "rural" are Census 2000 definitions based on population density. See: http://www.census.gov/geo/www/ua/ua_2k.html
} 
overrepresented among non-metropolitan enlistees across all branches. The overrepresentation is especially pronounced for Army and Air Force recruits (a 22\% and $23 \%$ proportional overrepresentation, respectively).

Table 4: Military enlistment by county non-metropolitan/metropolitan and rural concentration status for all military branches, 2004-2005

\begin{tabular}{|c|c|c|c|c|c|c|c|c|}
\hline & \multicolumn{4}{|c|}{ Percent of Recruits } & \multicolumn{4}{|c|}{$\begin{array}{l}\text { Ratio of Recruits to Population Age 18-24 } \\
\text { (Relative Risk of Enlistment) }\end{array}$} \\
\hline & Army & Marines $^{a}$ & Navy & Air Force & Army & Marines $^{a}$ & Navy & Air Force \\
\hline Total Number & 129,054 & 37,995 & 75,842 & 52,777 & & & & \\
\hline Non-metropolitan & $20 \%$ & $19 \%$ & $18 \%$ & $21 \%$ & 1.22 & 1.12 & 1.09 & 1.23 \\
\hline Metropolitan & $80 \%$ & $81 \%$ & $82 \%$ & $79 \%$ & 0.96 & 0.98 & 0.98 & 0.95 \\
\hline \multicolumn{9}{|c|}{ Rural Concentration ${ }^{\mathrm{b}}$} \\
\hline 0 (all urban) & $3 \%$ & $3 \%$ & $4 \%$ & $2 \%$ & 0.59 & 0.47 & 0.69 & 0.33 \\
\hline $.00-.09$ & $41 \%$ & $44 \%$ & $44 \%$ & $40 \%$ & 0.89 & 0.95 & 0.97 & 0.87 \\
\hline $.10-.19$ & $14 \%$ & $14 \%$ & $13 \%$ & $15 \%$ & 1.05 & 0.99 & 0.97 & 1.09 \\
\hline $.20-.29$ & $9 \%$ & $10 \%$ & $9 \%$ & $10 \%$ & 1.13 & 1.15 & 1.04 & 1.20 \\
\hline $.30-.39$ & $8 \%$ & $8 \%$ & $7 \%$ & $9 \%$ & 1.07 & 1.04 & 1.00 & 1.21 \\
\hline $.40-.49$ & $6 \%$ & $6 \%$ & $6 \%$ & $6 \%$ & 1.15 & 1.16 & 1.08 & 1.25 \\
\hline $.50-.59$ & $5 \%$ & $5 \%$ & $5 \%$ & $5 \%$ & 1.22 & 1.14 & 1.13 & 1.23 \\
\hline $.60-69$ & $5 \%$ & $4 \%$ & $4 \%$ & $5 \%$ & 1.35 & 1.21 & 1.15 & 1.35 \\
\hline $.70-.19$ & $3 \%$ & $3 \%$ & $3 \%$ & $3 \%$ & 1.24 & 1.16 & 1.19 & 1.26 \\
\hline $.80-.89$ & $2 \%$ & $2 \%$ & $2 \%$ & $2 \%$ & 1.52 & 1.55 & 1.43 & 1.50 \\
\hline $.90-.99$ & $1 \%$ & $1 \%$ & $1 \%$ & $1 \%$ & 1.54 & 1.42 & 1.47 & 1.39 \\
\hline 1 (all rural) & $2 \%$ & $2 \%$ & $2 \%$ & $2 \%$ & 1.38 & 1.24 & 1.33 & 1.34 \\
\hline
\end{tabular}

${ }^{\text {a }}$ Enlistment for 2005 only

${ }^{\text {b }}$ Census 2000 SF1, Broomfield County, CO, not included

The ratio of recruits to the population is unevenly distributed across the rural concentration continuum. Larger proportions of recruits come from more urban counties (especially counties with less than $10 \%$ of the population living in rural areas). Yet, recruits are proportionately overrepresented among more rural counties. For example, Army enlistment among the most rural counties ("all rural" in Table 4) is 38\% higher than its youth population and 54\% higher among counties with $90-99 \%$ rural 
population. The proportion of recruits generally increases linearly as rural concentration increases and the pattern is observed across all military branches. ${ }^{9}$

We disentangle the role of mortality and enlistment to further illustrate the differential impact of mortality for non-metropolitan troops and, in turn, nonmetropolitan communities. ${ }^{10}$ The estimates reported in Table 5 are calculated from data on Army deaths and enlistment between 2004 and 2007 since data was consistent for this branch and time period. Results reinforce the point that enlistment is considerably higher among non-metropolitan communities and that mortality is higher for troops coming from non-metropolitan communities. The total impact of the deaths and enlistment is three times higher for troops coming from non-metropolitan communities compared to troops from metropolitan communities $(.20$ versus .06 , per 1,000).

Table 5: Impact, total and disaggregated by enlistment and mortality for Army troops, 1 January 2004 - 31 December 2007

\begin{tabular}{lccc}
\hline & $\begin{array}{c}\text { Mortality } \\
(\text { per 1,000) }\end{array}$ & $\begin{array}{c}\text { Enlistment } \\
(\text { per 1,000) }\end{array}$ & $\begin{array}{c}\text { Impact } \\
(\text { per 1,000) }\end{array}$ \\
\hline Non-metropolitan & 16.40 & 12.01 & 0.20 \\
Metropolitan & 14.12 & 4.50 & 0.06 \\
\hline
\end{tabular}

Note: All non-metropolitan/metropolitan differences are statistically significant $(p<.05)$.

We also examined metropolitan and non-metropolitan deaths disaggregated by age, given popular media focus on recruitment of rural youths, but found no significant mortality differentials. Recruits from non-metropolitan areas had a higher relative risk of death in all age ranges, yet the proportions of deaths to total deaths in each group were comparable across metropolitan/non-metropolitan status. Nearly half of all fatalities were concentrated in the 20 to 24 year age grouping and the modal age of death was 21 for non-metropolitan and metropolitan personnel.

\footnotetext{
${ }^{9}$ Kane (2006) finds similar results when examining Zip Code Tabulated Areas (ZCTA). ZCTA capture populations at a finer scale of geography, yet data on troop deaths are not available by zip code. We maintain our analysis of enlistment at the county level because it corresponds with the analysis of troop mortality.

${ }^{10}$ Impact is expressed as mortality multiplied by enlistment where mortality is calculated as deaths by troops' home county divided by enlisted troops by county and enlistment is calculated as enlisted troops by county divided by county population age 20-34. Data on troop deaths are derived from iCasualties and the DOD, and enlistment estimates come from the National Priorities Project (NPP).
} 


\subsection{Rank}

Importantly, death rates account for differences in enlistment between non-metropolitan and metropolitan. ${ }^{11}$ We focus our attention on one of the risks identified in earlier research: rank. Buzzell and Preston state that "[o]ne of the oldest observations in the social sciences is that lower-ranking individuals experience a greater risk of death than higher-ranking individuals" (2007:559). Indeed, they find that enlisted troops in the Iraq War have significantly higher mortality than officers. For example, among Army personnel, the enlisted have $38 \%$ higher mortality than officers and, among the Marines, the enlisted have 33\% higher mortality. Some have suggested that individuals from non-metropolitan areas tend to enlist in the military as a means of gaining training and education (e.g., O'Hare and Bishop 2006). This would imply that non-metropolitan individuals enter the military as enlisted personnel (rather than as officers) and at lower ranks.

We examine whether a greater share of non-metropolitan deaths are concentrated among the enlisted and lower ranks. We disaggregate the number of deaths and calculate the proportion of deaths by rank for non-metropolitan and metropolitan troops. Results in Table 6 show mixed support. In general, a similar pattern of mortality is observed by rank for non-metropolitan and metropolitan troops. Relative to metropolitan troops, however, a greater concentration of deaths is found for nonmetropolitan troops in the Army, specifically among enlisted troops in the Army and, more specifically, Army Sergeants; $37 \%$ of all non-metropolitan deaths are concentrated among Army Sergeants compared to 30\% of all metropolitan deaths. There is a negligible difference between the proportions of total deaths among the lower ranked enlisted Army personnel. Similarly, there is little observed difference between non-metropolitan and metropolitan Army officers or among Marines, enlisted or officers. The differences between non-metropolitan and metropolitan mortality appear to be concentrated among Army Sergeants.

\footnotetext{
${ }^{11}$ A recent article in the New York Times reported that about $38 \%$ of active-duty soldiers who have served in Iraq since 2003 have been deployed more than once (Shanker 2008; http://www.nytimes.com/2008/04/06/ washington/06military.htmle $=1365134400 \& \mathrm{en}=\mathrm{d} 1 \mathrm{f} 48 \mathrm{ac} 4 \mathrm{ce} 0 \mathrm{f} 767 \mathrm{c} \& \mathrm{ei}=5088 \&$ partner $=\mathrm{rssnyt} \& \mathrm{emc}=\mathrm{rss}$, accessed May 2008). However, no reports or studies were found that address whether there is a disproportionate likelihood of repeat tours among rural troops which could increase their exposure to the risk of death.
} 
Curtis \& Payne: The differential impact of mortality of American troops in the Iraq War

Table 6: Number of deaths and relative mortality levels per deployment by military branch, rank and non-metropolitan/metropolitan status, Iraq War, 20 March 2003 - 31 December 2007

\begin{tabular}{|c|c|c|c|c|c|c|}
\hline & \multicolumn{3}{|c|}{ Number of deaths } & \multicolumn{2}{|c|}{$\begin{array}{l}\text { Percent of } \\
\text { Total Deaths }\end{array}$} & \multirow{2}{*}{$\begin{array}{c}\begin{array}{c}\text { Relative Risk of } \\
\text { Death Per Deployment }\end{array} \\
\text { Non-metro to Metro } \\
\end{array}$} \\
\hline & Non-metro & Metro & Total & Non-metro & Metro & \\
\hline Army (Active, Guard, Reserve) & 669 & 2075 & 2744 & 74.5 & 70.2 & 1.26 \\
\hline Enlisted & 620 & 1850 & 2470 & 69.0 & 62.6 & 1.31 \\
\hline Private, Private E-2 & 20 & 66 & 86 & 2.2 & 2.2 & 1.19 \\
\hline Private First Class & 106 & 319 & 425 & 11.8 & 10.8 & 1.30 \\
\hline Corporate/Specialist & 164 & 593 & 757 & 18.3 & 20.1 & 1.08 \\
\hline Sergeant $^{a}$ & 330 & 872 & 1202 & 36.7 & 29.5 & 1.48 \\
\hline Officer & 49 & 225 & 274 & 5.5 & 7.6 & 0.85 \\
\hline Second Lieutenant, First Lieutenant & 21 & 73 & 94 & 2.3 & 2.5 & 1.13 \\
\hline Captain & 8 & 76 & 84 & 0.9 & 2.6 & 0.41 \\
\hline Major, Colonel, General ${ }^{b}$ & 5 & 37 & 42 & 0.6 & 1.3 & 0.53 \\
\hline Warrant Officer & 15 & 39 & 54 & 1.7 & 1.3 & 1.51 \\
\hline Marines (Active, Reserve) ${ }^{c}$ & 196 & 780 & 976 & 21.8 & 26.4 & 1.09 \\
\hline Enlisted & 185 & 722 & 907 & 20.6 & 24.4 & 1.11 \\
\hline Private, Private First Class & 19 & 64 & 83 & 2.1 & 2.2 & 1.29 \\
\hline Lance Corporal & 86 & 354 & 440 & 9.6 & 12.0 & 1.05 \\
\hline Corporal & 47 & 176 & 223 & 5.2 & 6.0 & 1.16 \\
\hline Sergeant $^{d}$ & 33 & 128 & 161 & 3.7 & 4.3 & 1.12 \\
\hline Officer & 11 & 55 & 66 & 1.2 & 1.9 & 0.87 \\
\hline Second Lieutenant, First Lieutenant & 5 & 22 & 27 & 0.6 & 0.7 & 0.99 \\
\hline Captain & 4 & 23 & 27 & 0.4 & 0.8 & 0.75 \\
\hline Major, Colonel, General ${ }^{e}$ & 2 & 10 & 12 & $\begin{array}{l}0.2 \\
0.0\end{array}$ & $\begin{array}{l}0.3 \\
0.0\end{array}$ & 0.87 \\
\hline Navy (Active, Reserve) & 21 & 66 & 87 & 2.3 & 2.2 & 1.43 \\
\hline Air Force (Active, Guard, Reserve) & 12 & 33 & 45 & 1.3 & 1.1 & 1.41 \\
\hline AlI $^{\mathrm{f}}$ & 898 & 2955 & 3853 & & & 1.25 \\
\hline
\end{tabular}

${ }^{a}$ Includes Sergeant, Staff Sergeant, Sergeant First Class, Master Sergeant, and Sergeant Major

${ }^{\mathrm{b}}$ Includes Major, Lieutenant Colonel, Colonel, Brigadier General, Major General, Lieutenant General, and General

${ }^{\mathrm{c}}$ Total includes 3 Warrant Officer deaths

${ }^{\mathrm{d}}$ Includes Sergeant, Staff Sergeant, Gunnery Sergeant, Master Sergeant, and Sergeant Major

${ }^{\mathrm{e}}$ Includes Major, Lieutenant Colonel, Colonel, Brigadier General, Major General, Lieutenant General, and General

${ }^{\mathrm{f}}$ Metro total Includes one Coast Guard death 
We further examine mortality by calculating the relative risk of death for nonmetropolitan troops by deployment and find additional evidence of a nonmetropolitan/metropolitan disparity within rank. Results, also reported in Table 6, show that the relative risk of mortality is generally higher for non-metropolitan enlisted troops and lower for non-metropolitan officers. Differences are especially pronounced in the Army; non-metropolitan enlistees have a 31\% greater risk of mortality relative to their metropolitan counterparts. Among Army Sergeants - soldiers with the highest proportion of total deaths - non-metropolitan soldiers have a $48 \%$ greater risk of dying than metropolitan soldiers. Yet, among officers, non-metropolitan officers have a $15 \%$ lower risk of death than metropolitan officers. The non-metropolitan disadvantage decreases with rank.

\subsection{Race/Ethnicity}

The overall higher odds of mortality among non-metropolitan troops might be explained by race or ethnicity. Research has demonstrated race differences in military mortality; African Americans have lower mortality relative to whites (Gifford 2009; see also Binkin 1993 and Binkin et al. 1982). The race difference is attributed to variation in career intentions among military personnel. African Americans tend to volunteer for the military with the intention to pursue a career in the military whereas white volunteers are less career-focused. Career intentions make an impact on mortality through combat exposure; career-focused military personnel (such as officers) are less likely to be exposed to combat and, therefore, have a lower risk of mortality.

The race differences in career focus and accompanying combat exposure might contribute to non-metropolitan/metropolitan differences since race groups are not evenly distributed across metropolitan and non-metropolitan areas. For example, in 2000, the African American population was largely concentrated in metropolitan areas ( $90 \%$ versus $74 \%$ of whites). The uneven distribution of race groups and the military mortality risks associated with race might underlie the differences in the odds of mortality between metropolitan and non-metropolitan troops. African American personnel have lower mortality and the African American population is less represented in non-metropolitan areas; therefore, the higher risk race group (white) is disproportionately represented among the non-metropolitan areas.

The distribution of military deaths and the associated relative risk of death are calculated for each race/ethnic group as described in section 2.4, and reported in Table 7. ${ }^{12}$ Results support the anticipated race effect with an important caveat. Consistent

\footnotetext{
${ }^{12} \mathrm{We}$ also examined differences in the relative risk by age and sex (results not reported). Non-metropolitan male troops were $16 \%$ more likely to die than metropolitan male troops, whereas non-metropolitan females
} 
with previous research, African Americans have a lower risk of death than whites across the metropolitan dimension. Non-metropolitan white troops have a $52 \%$ higher risk of mortality than non-metropolitan African American personnel while metropolitan white personnel are 2.7 times as likely to die as metropolitan African Americans. In terms of raw proportions (not accounting for the disproportionate enlistment between race groups), deaths among white personnel comprise $89 \%$ of non-metropolitan casualties and $83 \%$ of all metropolitan casualties. Casualties among African American personnel, in contrast, account for $7 \%$ of all non-metropolitan deaths and $10 \%$ of metropolitan deaths. These findings are consistent with research demonstrating that African American personnel generally have lower mortality than white troops, perhaps due to career intentions and the associated combat exposure.

Table 7: Number of deaths and relative mortality levels by race/ethnicity and non-metropolitan/metropolitan status, Iraq War, 20 March 2003 - 31 December 2007

\begin{tabular}{|c|c|c|c|c|c|c|c|c|}
\hline \multirow[b]{2}{*}{ Race/Ethnicity } & \multicolumn{3}{|c|}{ Number of Deaths } & \multicolumn{2}{|c|}{ Percent of Total Deaths } & \multicolumn{3}{|c|}{ Relative Risk of Death per Deployment } \\
\hline & Non-metro & Metro & Total & Non-metro & Metro & $\begin{array}{c}\text { White/African } \\
\text { American Non- } \\
\text { metro }\end{array}$ & $\begin{array}{c}\text { White/African } \\
\text { American } \\
\text { Metro }\end{array}$ & $\begin{array}{c}\text { Non-metrol } \\
\text { Metro, Within } \\
\text { Race Group }\end{array}$ \\
\hline White & 768 & 2,153 & 2,921 & 85.5 & 72.9 & 1.52 & 2.70 & 1.02 \\
\hline African American & 61 & 305 & 366 & 6.8 & 10.3 & & & 1.80 \\
\hline American Indian & 15 & 25 & 40 & 1.7 & 0.8 & & & 0.93 \\
\hline Other & 20 & 119 & 139 & 2.3 & 4.0 & & & 2.49 \\
\hline Hispanic & 34 & 353 & 387 & 3.8 & 11.9 & & & 1.28 \\
\hline All & 898 & 2,955 & 3,853 & & & & & \\
\hline
\end{tabular}

Note: Non-metropolitan/metropolitan difference in Percent of Total Deaths is significant for all racial/ethnic groups $(p<.05)$.

The exception emerges when comparing the racial or ethnic groups by metropolitan status. The relative risk of mortality within racial or ethnic group shows a higher risk of death for African American non-metropolitan personnel compared to metropolitan African American personnel. Non-metropolitan African American personnel have an $80 \%$ higher risk of death than their metropolitan counterparts. Similarly, non-metropolitan Hispanic personnel have a $28 \%$ higher risk of mortality

had a $40 \%$ lower risk of mortality relative to metropolitan females. Non-metropolitan troops had a $10 \%$ to $33 \%$ higher risk of mortality for all age groups except for the 35-39 year-old age group; there was no difference in the risk of death between 35-39 year-old metropolitan and non-metropolitan troops. Troop counts by age and sex were found in Table B-22 of the report on the Population Representation in the Military Services 2005 (http://humrro03.securesites.net/poprep/poprep05/appendixb/b_22.html). 
than metropolitan Hispanic personnel (metropolitan areas are disproportionately represented among Hispanics). In contrast, white personnel from non-metropolitan areas have virtually the same risk of death as metropolitan whites ( $2 \%$ higher risk). ${ }^{13}$

The results show that the African American race effect cited in prior research (overall lower African American mortality because the population is less likely to engage in combat) may be a metropolitan race effect. That is, career intentions might vary among African Americans according to metropolitan status; metropolitan African Americans might select the career path and, therefore, experience lower exposure to combat whereas non-metropolitan African Americans might not pursue a military career and, in turn, experience higher exposure to combat. The non-metropolitan disadvantage persists for African Americans; non-metropolitan African American (and Hispanic) personnel are at a higher risk of death than their metropolitan counterparts.

Further, the findings indicate that the non-metropolitan disadvantage is due to differences in mortality among the non-white military population. There is virtually no difference in the relative risk of death between non-metropolitan and metropolitan white personnel. Instead, metropolitan differences are found for racial or ethnic groups that are typically underrepresented in non-metropolitan areas. African American, Hispanic, and other (mostly Asian American) personnel from non-metropolitan areas have a significantly higher risk of mortality compared to their race/ethnic-specific metropolitan counterparts.

\section{Conclusion}

The disaggregated analysis of mortality among US military troops suggests that nonmetropolitan areas are experiencing a higher cost of the Iraq War. Troops from nonmetropolitan counties have higher rates of death regardless of cause or military branch. Death rates inherently adjust for differential enlistment, suggesting that nonmetropolitan troops are at a greater risk of death after accounting for higher enlistment. This is an especially important point because enlistment receives central focus in popular accounts of metropolitan/non-metropolitan differences in military deaths.

The greatest impact of military deaths are felt by non-metropolitan counties, with the largest brunt experienced by counties within the Great Plains and the Upper Midwest regions. Military deaths are largely concentrated among Army personnel for non-metropolitan and metropolitan troops, although a higher concentration is observed for non-metropolitan troops, especially enlisted Army Sergeants; nearly $40 \%$ of all non-

\footnotetext{
${ }^{13}$ Among American Indians, unlike any other race group, those from non-metropolitan areas have a lower risk $(7 \%)$ of death than their metropolitan counterparts. The "other" category is difficult to interpret, but the non-metropolitan population is 2.5 times as likely to die as the metropolitan population.
} 
metropolitan deaths are concentrated among this group. The relative risk of death is higher among non-metropolitan enlistees and lower among non-metropolitan officers compared to metropolitan enlistees. The non-metropolitan disadvantage in risk of death decreases with rank; rural officers appear to have an advantage over their urban counterparts.

Race/ethnic differences are found and are consistent with prior research with one important qualification. Non-metropolitan and metropolitan African American personnel have a lower risk of mortality than their respective white counterparts. Within race/ethnic group comparisons, however, demonstrate that the non-metropolitan disadvantage persists for African American personnel (as well as Hispanic and "Other") but not whites. Non-metropolitan African Americans have an estimated $80 \%$ higher risk of death than African Americans from metropolitan areas, while there is a comparatively negligible difference $(2 \%)$ between non-metropolitan and metropolitan white personnel.

Results provide an important nuance to the previously documented race effect and insight about the non-metropolitan disadvantage. Prior findings may be indicative of a metropolitan race effect but they do not apply to the non-metropolitan dimension. African Americans from metropolitan areas may intend to pursue a military career and, therefore, have a lower exposure to combat. Different career motivations may characterize the non-metropolitan African American military population. Whatever the source of higher mortality among non-metropolitan African Americans, the findings suggest that much of the overall non-metropolitan disadvantage is due to higher mortality among African American and Hispanic troops rather than whites. Additional data, namely data on the hometown of all enlisted soldiers, is necessary to fully elaborate the career path thesis.

These data limit our ability to comment on why non-metropolitan troops experience higher death rates and, in turn, why rural communities bear a disproportionate burden of war. Perhaps there are systematic differences in the quality of training, the riskiness of missions, or other factors that put non-metropolitan military personnel (and especially non-white non-metropolitan military personnel) at a greater risk of mortality than metropolitan personnel. Results demonstrate that the differential risk is worthy of focus in future research.

As earlier research and popular accounts have noted, death is just one of the potential outcomes of active military service. Injuries, physical and psychological, are other likely consequences of war. Each outcome has important implications for the veterans as well as the communities to which they return, including the extent to which support services are available to veterans and their families. Rural communities may be doubly hit by the war, since non-metropolitan communities experience greater loss and have fewer resources with which to respond. The ability to recover from loss due to 
death or injury is yet another potential aspect by which the effects of war have a larger impact on smaller communities.

\section{Acknowledgements}

This work was supported by the Wisconsin Agricultural Experiment Station. The authors are grateful to the editor and reviewers at Demographic Research and to Amy Kate Bailey, Felix Elwert, Michel Guillot, Richelle Winkler, and Halliman Winsborough for their valuable comments on earlier drafts, and to Jennifer Huck for her indispensable research assistance. 


\section{References}

Bachman, J.G., Segal, D.R., Freedman-Doan, P., and O'Malley, P.M. (2000). Who Chooses Military Service? Correlates of Propensity and Enlistment in the US Armed Forces. Military Psychology 12(1): 1-30. doi:10.1207/S15327876MP 1201 1.

Binkin, M. (1993). Who Will Fight the Next War? Washington D.C.: The Brookings Institution.

Binkin, M., Eitelberg, M.J., Schexnider, A.J., and Smith, M.M. (1982). Blacks and the Military. Washington D.C.: The Brookings Institution.

Buzzell, E. and Preston, S.H. (2007). Mortality of American Troops in the Iraq War. Population and Development Review 33(3): 555-566. doi:10.1111/j.17284457.2007.00185.x.

Dale, C. and Gilroy, C. (1984). Determinants of Enlistments: A Macroeconomic TimesSeries View. Armed Forces \& Society 10(2): 192-210. doi:10.1177/0095327X8401000203.

Eberhardt, M.S., Ingram, D.D., Makuc, D.M., et al. (2001). Urban and Rural Health Chartbook. Health, United States, 2001. Hyattsville, Maryland: National Center for Health Statistics. http://www.cdc.gov/nchs/data/hus/hus01.pdf.

Gifford, B. (2009). Combat Casualties and Race: What Can We Learn from the 20032004 Iraq Conflict? Armed Forces \& Society 31(2): 201-225. doi:10.1177/0095327X0503100203.

Helseth, C. (2007a). Rural Vets Return Home to Face New Battles. The Rural Monitor Spring(2007): 3-4 and 12

Helseth, C. (2007b). War Has Big Impact in Rural Areas. The Rural Monitor Spring(2007): 1-2 and 12 .

Kane, T. (2005). Is Iraq a Poor Man's War? Washington D.C.: The Heritage Foundation. (Webmemo \#922).

Kane, T. (2006). Who Are the Recruits? The Demographic Characteristics of U.S. Military Enlistment, 2003-2005. Washington D.C.: The Heritage Foundation. (A Report of The Heritage Center for Data Analysis CDA06-09).

Mark, J. (2007). Small Towns, Big Sacrifices. The Nation March 17, 2007 http://www.cbsnews.com/stories/2007/03/16/opinion/main2578529.shtml (accessed April 2008). 
O'Hare, W. and Bishop, B. (2006). U.S. Rural Soldiers Account for a Disproportionately High Share of Casualties in Iraq and Afghanistan. Carsey Institute Fact Sheet 3(Fall 2006).

Preston, S.H., Heuveline, P., and Guillot, M. (2001). Demography: Measuring and Modeling Population Processes. London: Basil Blackwell.

Segal, D.R. and Segal, M.W. (2004). America's Military Population. Population Bulletin 59(4).

Shanker, T. (2008). Army is Worried by Rising Stress of Return Tours to Iraq. The New York Times April 6, 2008. http://www.nytimes.com/2008/04/06/washington /06military.html?ex=1365134400\&en=d1f48ac4ce0f767c\&ei=5088\&partner=rs snyt\&emc=rss (accessed May 2008).

Teachman, J.D., Call, V.R.A., and Segal, M.W. (1993). The Selectivity of Military Enlistment. Journal of Political and Military Sociology 21(2): 287-309.

U.S. Census Bureau. (2002). Census 2000 Summary File 1 [United States], prepared by the U.S. Census Bureau.

White, K.J.C. and Guest, A.M. (2003). Community Lost or Transformed? Urbanization and Social Ties. City \& Community 2(3): 239-259. doi:10.1111/15406040.00053 .

Zeitlin, M., Lutterman, K.G., and Russell, J.W. (1973). Death in Vietnam: Class, Poverty, and the Risks of War. Politics \& Society 3(3): 313-328. doi:10.1177/003232927300300303. 
Curtis \& Payne: The differential impact of mortality of American troops in the Iraq War 